\title{
Clinicopathological Conference Report
}

\section{Tumor Clinic Unit 1}

\section{Dysgerminoma in Ovarian Dysgenesis with Pregnancy with in vitro Fertilization with Donor Oocyte}

\author{
Tumor Clinic Unit 1 \\ Presenters: \\ Moderator: \\ Gyne Unit 1 Faculty: \\ Cytology \& Gyne-Pathology Unit Faculty: \\ Radiotherapy Unit Faculty:
}

\author{
Date: $28 / 2 / 2017$ \\ Dr Athokpam Lenin Luwang ${ }^{1}$ and Dr Pankaj Kumar² \\ Dr Aashima Arora $^{3}$ \\ Dr Jasvinder Kalra ${ }^{4}$, Dr Rashmi Bagga ${ }^{5}$, Dr PK Saha ${ }^{6}$, Dr Rimpi Singla ${ }^{7}$ \\ Dr Arvind Rajwanshi ${ }^{8}$, Dr Radhika Srinivasan ${ }^{9}$, Dr Pranab Dey ${ }^{10}$, Dr Nalini Gupta $^{11}$ \\ Dr Sushmita Ghoshal ${ }^{12}$, Dr Bhavana Rai ${ }^{13}$, Dr Renu Madan ${ }^{14}$
}

\section{INTRODUCTION}

Primary amenorrhea may be due to various causes and during its workup, if gonadotropin levels are increased, it is diagnosed as hypergonadotropic hypogonadism. The next step is to check for a Y chromosome by doing a karyotype as many of such "women" will be having an XY karyotype and hypergonadotropic hypogonadism due to gonadal dysgenesis. They have an over $25 \%$ chance of having a germ cell tumor in the dysgenetic gonads, which should be removed after pubertal development has occurred.

\section{CASE REPORT}

A 34-year-old female, with one living child, was referred to the Postgraduate Institute of Medical Education and Research (PGIMER), Chandigarh, India, from a private hospital on day 41 after cesarean section along with right salpingo-oophorectomy (done on January 3, 2017). She had been married for 10 years. She had primary amenorrhea with no history of cyclical pain abdomen. Her breasts and pubic/axillary hair were Tanner 2. She gave history of withdrawal bleeding on combined oral pills; however, she

\footnotetext{
1,2Junior Resident, ${ }^{3,7,13,14}$ Assistant Professor, ${ }^{4,5,8-12}$ Professor

${ }^{6}$ Associate Professor

1,3-7 Department of Obstetrics and Gynaecology, Postgraduate Institute of Medical Education and Research, Chandigarh, India

${ }^{2}$ Department of Pathology, Postgraduate Institute of Medical Education and Research, Chandigarh, India

8-11 Department of Cytology and Gynaepathology, Postgraduate Institute of Medical Education and Research, Chandigarh, India

${ }^{12-14}$ Department of Radiotherapy, Postgraduate Institute of Medical Education and Research, Chandigarh, India

Corresponding Author: Aashima Arora, Assistant Professor Department of Obstetrics and Gynaecology, Postgraduate Institute of Medical Education and Research, Chandigarh, India e-mail: aashicool184@gmail.com
}

could not conceive. An ultrasound showed bilateral small ovaries (right ovary $1.7 \times 0.8 \mathrm{~cm}$, left ovary $1.7 \times 0.9 \mathrm{~cm}$ ) and a small uterus. Her follicle-stimulating hormone (FSH) was increased (64.16) and she was diagnosed as having hypergonadotropic hypogonadism. She was also found to have hypothyroidism (thyroid-stimulating hormone 6.47).

She adopted a girl child in 2012. She was again evaluated in January 2016 in a private clinic. Her FSH was increased to 67.93 (January 14, 2016). She was given option for in vitro fertilization (IVF) with a donor egg.

The first cycle of IVF with donor egg ended in a spontaneous abortion at 8 weeks gestation. The second cycle of IVF with donor egg was done in May 2016. Her antenatal period was uneventful and she received progesterone supplements throughout the pregnancy. An elective cesarean section was done on January 3, 2017 at 37 weeks gestation under spinal anesthesia. Intraoperatively, there was no free fluid. There was a solid right ovarian tumor $(6 \times 6 \mathrm{~cm})$ with intact capsule and left ovary was a streak (just like a thread). Bilateral tubes and uterus were normal in morphology. Right salpingo-oophorectomy was done. She delivered a baby boy of $2.5 \mathrm{~kg}$ with Apgar score of 8.9. Histopathology of the right ovarian tumor showed a dysgerminoma (grade 1). She was referred to PGIMER.

Her general examination was normal and body mass index was 24 . Her abdomen was soft and the cesarean scar had healed well. On pelvic examination, the vagina and cervix were normal. A papanicolaou test (PAP) smear was atrophic. The uterus was anteverted and normal sized. There was no adnexal mass. A karyotype was done in PGIMER which was 46XY, hence, making a diagnosis of Swyer syndrome. She was planned for surgery to remove the left gonad, exploration and staging of the tumor.

\section{DISCUSSION}

The cause of primary amenorrhea in one-third of patients is ovarian. History and physical examination are the 
most important step in evaluation. ${ }^{1}$ Absence of secondary sexual characters and lack of history of cyclical pain abdomen pointed to an endocrinological cause of amenorrhea. Markedly elevated FSH levels in the presence of uterus and small ovaries on ultrasound confirmed a diagnosis of hypergonadotropic hypogonadism. ${ }^{2}$

The causes of hypergonadotropic hypogonadism are gonadal agenesis, gonadal dysgenesis, ovarian enzymatic deficiency (17 $\alpha$-hydroxylase deficiency, 17,20-lyase deficiency, aromatase deficiency), and chemotherapy or radiotherapy. ${ }^{2}$ This patient had streak ovaries with small uterus with no history of chemotherapy or radiotherapy. Ovarian enzymatic deficiency is very rare, ovarian size is usually normal, and is usually associated with other features like hypertension, electrolyte imbalance, fluid overload, etc. Hence, a clinical diagnosis of gonadal dysgenesis was made in this patient at her first evaluation in PGIMER.

The etiology of gonadal dysfunction is determined by karyotype as the causes include gonadal dysgenesis $45 \mathrm{X}$ (Turner syndrome), pure gonadal dysgenesis (46XX and 46XY), and mixed gonadal dysgenesis. Turner syndrome is usually associated with characteristic physical characters called as Turner's stigmata while mixed gonadal dysgenesis mostly presents as male phenotype. The karyotype confirmed the diagnosis to be pure gonadal dysgenesis 46XY, also called as Swyer syndrome.

The etiology of 46XY pure gonadal dysgenesis is thought to be a mutation of short arm of $Y$ chromosome involving sex-determining region of Y chromosome (SRY) gene in $15 \%$ of cases or a mutation in other genes that leads to inhibition of SRY function or mutation of SRY function. ${ }^{3}$ When this gene is defective, the indifferent gonads fail to differentiate into testes in an XY (genetically male) fetus. Without testes, no testosterone or anti-Müllerian hormone $(\mathrm{AMH})$ is produced. Without testosterone, the Wolffian ducts fail to develop, so no internal male organs are formed. Also, the lack of testosterone means that no dihydrotestosterone is formed and consequently, the external genitalia fail to virilize, resulting in normal female genitalia. Without $\mathrm{AMH}$, the Müllerian ducts develop into normal internal female organs (uterus, fallopian tubes, cervix, and vagina).

The incidence of Swyer syndrome is 1 in 80,000 to 1 in 100,000 individuals. ${ }^{4,5}$ The presence of $Y$ chromosome in patients with 46XY gonadal dysgenesis increases the risk of gonadal tumors, mainly gonadoblastoma (20-30\%), and may give rise to malignant tumor like dysgerminoma. ${ }^{6,7}$ A prophylactic bilateral salpingogonadectomy must be advised to these patients in order to prevent malignant transformation. ${ }^{8}$

According to the standard guidelines, gonadectomy is not indicated in patients diagnosed as pure gonadal dysgenesis (46XX type). Gonadectomy per se is also not indicated in Turner syndrome. However, 5 to $20 \%$ are associated with all or parts of $\mathrm{Y}$ chromosome. ${ }^{9}$ Also recently, cases are reported with dysgerminoma occurring in pure gonadal dysgenesis, 46XX without $Y$ component, ${ }^{10,11}$ and mosaicism of Turner syndrome $(X O, X Y) \cdot{ }^{12,13}$ Hence, detection of $Y$ chromosome is extremely important. Karyotyping by cytogenetic analysis may miss small part or portion of $\mathrm{Y}$ chromosome. Molecular techniques like fluorescent in situ hybridization and polymerase chain reaction are better as they can detect part or portion of $Y$ chromosome by analyzing Y chromosome loci (SRY, ZFY, DYZ3, DYZ1, and DY132).${ }^{14}$

\section{REFERENCES}

1. Fritz MA, Leon S. Clinical gynecologic endocrinology and infertility. 8th ed. Philadelphia: Lippincott Williams \& Wilkins; 2011. p. 438-450.

2. Berek JS. Berek and Novak's gynecology. 15th ed. Philadelphia: Lippincott Williams \& Wilkins; 2012. p. 1036-1044.

3. Harley VR, Clarkson MJ, Argentaro A. The molecular action and regulation of the testis determining factors, SRY (sexdetermining region on the $\mathrm{Y}$ chromosome) and SOX9 [SRY related high-mobility group (HMG) box 9]. Endocr Rev 2003 Aug;24(4):466-487.

4. Da Silva Rios S., Mazzaro Monteiro I.C., Gonçalves Braz dos Santos L., Garcia Caldas N., Rios Chen A.C., Rios Chen J. et al. A Case of Swyer Syndrome Associated with Advanced Gonadal Dysgerminoma Involving Long Survival. Case Rep Oncol 2015;8:179-184.

5. Chander A, Shri R, Muthuvel A, Veluswamy C. Rare case of complete gonadal dysgenesis $46 \mathrm{XY}$, Swyer syndrome. Int J Res Med Sci 2017;5(2):714-716.

6. Fritz MA, Leon S. Clinical gynecologic endocrinology and infertility. 8th ed. Philadelphia: Lippincott Williams \& Wilkins; 2011. p. 463.

7. Coutin AS, Hamy A, Fondevilla M, Savigny B, Paineau J, Visset J. Pure 46XY gonadal dysgenesis. J Gynecol Obstet Biol Reprod (Paris) 1996;25(8):792-796.

8. Nadereh B, Zarchi MK. Dysgerminoma in three patients with Swyer syndrome. World J Surgical Oncol 2007;5:71. doi:10.1186/1477-7819-5-71.

9. Fritz MA, Leon S. Clinical gynecologic endocrinology and infertility. 8th ed. Philadelphia: Lippincott Williams \& Wilkins; 2011. p. 461.

10. Namavar JB, Mohit M, Kumar PV. Familial dysgerminoma associated with 46XX pure gonadal dysgenesis. Saudi Med J 2005 May;26:872-874.

11. Letterie GS, Page DC. Dysgerminoma and gonadal dysgenesis in a 46XX female with no evidence of $Y$ chromosome DNA. Gynecol Oncol 1995 Jun;57(3):423-425.

12. Kota SK, Kotni G. Dysgerminoma in a female with Turner syndrome and Y chromosome material. Indian J Endocrinol Metab 2012 May-Jun;16(3):436-440.

13. Pfeiffer R.A., Tietze U., Krone H.A., Schaaff A., Dhom G., Peter H. Invasive dysgerminoma in a girl with $45, \mathrm{X} / 46, \mathrm{X}$; mar mosaicism. Arch. Gynecol. (1983) 233:141-147.

14. Cortés-Gutiérrez EI, Herrera-Bartolo R, Dávila-Rodríguez MI, Palacios-Saucedo GC, Vargas-Villarreal J, Romero-Villarreal JB. Molecular detection of cryptic Y-chromosomal material in patients with Turner syndrome. Oncol Rep 2012 Oct;28(4): 1205-1210. 